\title{
Reflexões sobre a humanização na assistência de enfermagem obstétrica na visão do enfermeiro obstetra
}

\author{
Maria Adriana Correa Borba Alves*, Umberto Gazi Lippi, D.Sc.**, Selma Aparecida Lagrosa Garcia, M.Sc.***
}

* Enfermeira Obstetra, Mestranda do Programa de Pós-Graduação em Ciências da Saúde do Instituto de Assistência Médica ao Servidor Público Estadual de São Paulo Programa de Pós-Graduação em Ciências da Saúde (IAMSPE), **Médico, Professor em Medicina pela Escola Paulista (UNIFESP), Livre Docente em Obstetricia pela Faculdade de Medicina de Taubaté,

***Enfermeira Obstetra, IAMSPE

\section{Resumo}

Objetivo: Identificar através da análise da literatura aspectos da humanização na assistência obstétrica e descrever a importância da inter-relação entre os profissionais de saúde e a parturiente durante o trabalho de parto. Métodos: A metodologia utilizada foi a revisão sistemática da literatura, por meio de consulta a bases de dados. Resultados: Com a modernizaçáo e a utilização de crescente aparato tecnológico, tem se notado certa distância entre profissionais e pacientes. Aqueles têm sempre que estar atentos à aparelhagem e com limitação do tempo a ser disponibilizado na humanizaçáo devido ao grande número de atividades que necessitam desenvolver, deixando a desejar no aspecto do relacionamento. Nota-se, no entanto, que políticas de humanização têm sido criadas com enfoque em capacitaçôes e atualizaçôes para profissionais e um real investimento nessa questão tem mostrado resultados positivos. Conclusão: Assim, observa-se que a teoria, ideal e humanista, encontra-se além do que se observa na prática. Portanto, é necessário que o empenho seja constante na busca da assistência humanizada e que tal modelo de atenção se faça com base na inter-relação entre os profissionais de saúde e suas pacientes, inter-relaçóes estas que constituem o alicerce do processo de cuidar.

Palavras-chave: humanização, assistência, trabalho de parto, enfermagem obstétrica.

\section{Abstract}

\section{Reflections on humanization in nursing obstetric care: from nurse's point of view}

Aim: To identify importance of the interrelationship between healthcare professionals and the patient, and the humanization of obstetric care during labor. Method: The methodology used was that of literature review. Results: With modernization and the increasing use of technological devices, an estrangement can be noted between professionals and patients. The former must always be watching the functioning of the equipment and, due to the large number of tasks they must carry out, not much time is left for humanization, which leaves much to be desired in terms of human relationships. Humanization policies have been introduced, and investments focusing on training and updating for healthcare 
professionals have shown positive results. Results: It is observed that the theory, ideal and humane, is ahead of what can be seen in practice. Nevertheless, it is important that a constant commitment to the pursuit of humanized care be made, and that such a model of healthcare be based on the interrelationship between healthcare professionals and their patients. Such interrelationships are the foundation of the care giving process. Fundamentally, for this approach, the process of humanization in obstetric care requires the activities of nurses that operate in obstetrics.

Key-words: humanization, assistance, obstetric labor, obstetric nursing.

\section{Resumen}

\section{Reflexiones sobre la humanización en la atención de enfermería obstétrica: desde el punto de vista del enfermero obstetra}

Objetivo: Identificar por medio de análisis de la literatura aspectos de la humanización en la atención obstétrica y describir sobre la importancia de la interrelación entre profesionales de la salud y la parturiente durante el parto. Métodos: La metodología utilizada fue de revisión sistemática de la literatura a través de consulta a la base de datos electrónicos. Resultados: Con la modernización y la creciente utilización de herramientas tecnológicas, se ha notado la distancia entre profesionales y pacientes. Los profesionales deben siempre estar atentos a la tecnología, con limitación de tiempo para acciones de humanización, debido al gran número de actividades que desarrollan, dejando mucho que desear en el aspecto de la relación. Políticas de humanización han sido creadas y las inversiones con enfoque en la capacitación y actualización para profesionales han mostrado resultados positivos. Conclusión: Se observa que la teoría, ideal y humanista, está por delante de lo que se observa en la práctica. A pesar de ello, es necesario que el compromiso en la búsqueda de asistencia humanizada sea constante y que un modelo de atención se base en la interrelación entre los profesionales de la salud y sus pacientes, interrelaciones que constituyen la piedra angular del proceso de atención.

Palabras-clave: humanización, atención, trabajo de parto, enfermería obstétrica.

\section{Introdução}

A enfermagem constitui uma profissão secular que mantém estreita relação com a história da civilização. Tem papel preponderante por ser uma atividade que busca promover o bem-estar do ser humano, considerando sua liberdade, unicidade e dignidade. Atua na promoção da saúde, prevenção de enfermidades, processos educativos, nos cuidados durante o transcurso de doenças e agravos, nas incapacidades e no processo de morrer.

A Revolução Industrial e a Segunda Guerra Mundial uniram ciência e tecnologia, fazendo com que diversas áreas do conhecimento utilizassem equipamentos cada vez mais sofisticados. A partir de então a profissão teve um impulso considerável, em pesquisas, técnicas e novos conceitos; por outro lado, a ciência obteve um grande avanço desde o momento em que se aliou à tecnologia, beneficiando-se dos princípios científicos e dos equipamentos, desde os mais simples até os mais sofisticados. Todo este avanço promoveu a ascensão e desenvolvimento em vários campos de conhecimento, surgiram então varias indagaçôes sobre as reais contribuiçôes destas mudanças para conquistas da felicidade do ser humano [1].

Quando se reflete sobre humanizar, um dos primeiros aspectos que vem ao pensamento é tratar a pessoa de forma singular, dar atençáo, expressar gestos amáveis, ter desvelo [2]. Para Oliveira [3] significa colocar a cabeça e o coração na tarefa a ser desenvolvida, entregar-se de maneira sincera e leal ao outro e saber ouvir com ciência e paciência as palavras e os silêncios.

Pode-se também entender humanizar como a possibilidade de estar atento às condiçóes e as necessidades do outro, já que a base das atividades do profissional da saúde é a relação humana. A capacidade de responder ao sofrimento humano, ser colaborativo, ser responsável pelas suas açôes, 
ter respeito pelos que estáo a sua volta, faz com que a humanização seja caracterizada por atitudes, proporcionando, assim, um atendimento integral e não fragmentado. A partir da integralidade se reconhece a necessidade do outro, desencadeando atitudes e ações humanizadas [4].

O ser humano necessita de cuidados desde o nascimento até a morte. $\mathrm{O}$ cuidado

significa uma condição existencial básica. $\mathrm{Ou}$ seja, um fenômeno que é a base desencadeadora da existência humana. Por isso, a humanização e o cuidado são coisas indissociáveis [5].

A humanização é como um valor de respeito à vida humana que engloba aspectos sociais, éticos, educacionais e circunstâncias psíquicas presentes em todo ser humano, e, consequentemente, nas relaçóes interpessoais. Este valor deve estar presente e deve ser complementado por aspectos técnico-científicos. Humanizar, segundo Barbosa e Silva [6], envolve respeitar a individualidade do ser humano e construir "um espaço concreto nas instituiçóes de saúde, que legitime o humano das pessoas envolvidas".

A ideia da humanização no parto vem do fato de que muitos serviços médicos ignoram as recomendaçôes do Ministério da Saúde do Brasil e outros órgáos que normatizam o atendimento ao parto [7].

A humanização na assistência obstétrica tem evoluído e ganha cada vez mais espaço. O conceito encontra-se bem delimitado. Apesar de diferentes teorias, todas direcionam ao mesmo propósito, contudo apesar de conceitos bem difundidos, na prática ainda se encontra dificuldade na implementação, tanto na organização dos serviços de saúde, na falta de conhecimento e de sensibilidade dos profissionais da saúde, quanto na importância do atendimento humanizado, ainda são desafios a serem superados [7].

A terminologia "humanizar" e seus derivados têm adquirido sentidos igualmente diversos, em contextos distintos. No que concerne ao fenômeno do parto, refere-se a uma atenção que parte do reconhecimento dos direitos fundamentais de mães e crianças e do direito à tecnologia apropriada na assistência. Esse conjunto de demandas incluiria o direito à escolha de local, pessoas e formas de assistência no parto; a preservação da integridade corporal de máes e crianças; o respeito ao parto como experiência altamente pessoal, social e familiar; a assistência à saúde e os apoios emocionais, sociais e materiais no ciclo gravídico-puerperal; a proteçáo contra abuso e negligência. São práticas que vão tornar uma assistência diferenciada da tradicional, trazendo benefícios à parturiente, ao recém-nascido e à família [7].

O Código de Ética no Brasil, através da Resolução n. ${ }^{\circ 311 / 2007,(C O F E N, ~ 2007) ~[8], ~ c o l o c a ~}$ que "o profissional da enfermagem respeita a vida a dignidade e os direitos da pessoa humana, em todo seu ciclo vital, repele a discriminação de qualquer natureza, assegura ao cliente uma assistência de enfermagem livre de danos decorrentes de imperícia, negligência ou imprudência, cumpre e faz cumprir os preceitos éticos e legais da profissão, exercendo a enfermagem com justiça, competência, responsabilidade e honestidade".

Cuidar de forma mais digna requer uma interação e o estabelecimento de vínculos entre a equipe e a família, no intuito de promover uma comunicação mais aberta e amenizar o estresse do cliente frente a sua patologia e ambiente desconhecido ou hostil.

Segundo o Ministério da Saúde do Brasil, a humanização da assistência obstétrica e neonatal é a condição para o adequado acompanhamento do parto, puerpério e recém-nascido. Receber com dignidade a mulher e a criança é uma obrigação das Unidades de Saúde. A adoção de práticas humanizadas e seguras implica organizaçáo de rotinas, procedimentos e estrutura física, bem como a incorporação de condutas acolhedoras e pouco intervencionistas - (Portaria 569 - 01/06/2000, Anexo II) [9].

Com o intuito de melhorar a qualidade da assistência e garantir que a mulher passe a ser vista como protagonista do seu processo de saúde, no âmbito da atenção obstétrica, diversas estratégias vêm sendo desenvolvidas pelo Ministério da Saúde do Brasil desde a década de 80 , com programas para humanizar o parto e nascimento nas maternidades públicas, portarias que estimulem a criação de centros de parto normal com a atuação do enfermeiro obstétrico. A estratégia mais atual é a Rede Cegonha que visa assegurar à mulher o direito ao planejamento reprodutivo com atenção à gravidez, parto, puerpério e também à criança o direito ao nascimento seguro. Todas estas medidas visam à humanização dos serviços de saúde para reduzir os coeficientes de mortalidade materna e neonatal, intervenções desnecessárias e o alto índice de cesáreas $[10,11]$.

Desta forma, foi possível compreender, à luz das reflexóes teóricas dos autores neste trabalho citados, que 
a humanização surge como um desafio no novo século para os profissionais de saúde, pois há, atualmente, enfoque na complexidade tecnológica, fragmentação do cuidado em visóes isoladas, áreas específicas. Além disso, há deficiências estruturais do sistema de saúde como um todo; faltam filosofias de trabalho e de ensino voltadas à humanização de maneira efetiva. A inclusão de programas de atenção humanizada a parturição na formação de profissionais da saúde, educação permanente da equipe de saúde, falta de protocolos, são açóes que se desenvolvidas propiciam um atendimento humanizado. A educação favorece a realização do ser humano no sentido de aprender a ser, levando a formação de um profissional capaz de oferecer uma assistência mais humanizada [7].

Sendo assim, para se prestar uma assistência de enfermagem humanizada no período puerperal é necessário que os profissionais adotem práticas cujos aspectos físicos, sociais e subjetivos sejam partes integrantes do cuidado de saúde, beneficiando tanto o cliente quanto o profissional, atuando como uma ferramenta para a recuperação e a manutenção da saúde [12].

Neste sentido, pode-se, também, entender que o cuidar de enfermagem de forma humanizada em obstetrícia significa prestar cuidados mais próximos ao paciente; o profissional deve ser capaz de entender a si mesmo e ao outro, ampliando esse conhecimento na forma de ação e tomando consciência dos valores e princípios que norteiam essa relação. Neste contexto, respeitar o paciente é componente primordial no tocante a cuidados humanizados. Implica em fazê-lo de maneira holística, escutar o que ele tem a dizer, procurando sempre interpretar o que ouvir e ter compaixão, ser sempre tolerante, honesto, atencioso, atender e entender a necessidade do autoconhecimento para poder respeitar a si próprio e, então, respeitar o outro.

Diante do exposto, surge interesse em estudar e aprofundar esse assunto, uma vez que se evidencia sua grande importância, e que a humanização constitui ferramenta preciosa dentro do contexto da assistência obstétrica.

O objetivo deste trabalho é identificar, por meio da análise teórica, a importância da humanização na assistência obstétrica e apresentar aspectos relevantes da inter-relação entre os profissionais de saúde durante o trabalho de parto e o parto, observando se ocorre a concretização do atendimento e assistência humanizada no contexto físico, mental, emocional e social.
Serão apresentadas reflexóes sobre a importância do humanizar em obstetrícia, tornando-a, por meio de um processo saudável de comunicação, a protagonista do evento que envolve atendimento integrado obstétrico e neonatal.

\section{Material e métodos}

O presente estudo trata-se de uma revisão sistemática. A pesquisa bibliográfica consiste em analisar a bibliografia já publicada relacionando-a ao tema proposto, tendo como finalidade manter o pesquisador informado sobre tudo o que foi escrito, dito ou filmado sobre determinado assunto. A pesquisa bibliográfica descritiva narra os fatos encontrados através de registros publicados, possibilitando alcançar o conhecimento, o procedimento da pesquisa, e possibilitar o conhecimento comprovado daquilo que se quer demonstrar [13].

A pesquisa foi realizada no site da Biblioteca Virtual em Saúde, o qual disponibiliza um acesso livre e gratuito à informação técnico-científica gerada pelas instituiçóes acadêmicas e pelo Sistema Único de Saúde do Brasil, base online Scielo e Google Acadêmico. Foi ampliada por meio de sites governamentais onde foi realizada a busca por informaçóes ainda não encontradas.

A coleta dos dados foi realizada no período de 2007 a 2015. Foram utilizadas as seguintes palavras-chave no descritor: "humanização", "assistência", "trabalho de parto" e "enfermagem obstétrica". As publicaçóes analisadas foram limitadas no período de 2007 a 2014.

Após a seleção dos artigos pertinentes, foi realizada a leitura, interpretação e análise do material. Posteriormente foi feito o fichamento para a organização dos dados que subsidiou construção do texto [14].

\section{Conceito de humanização}

Há muitas décadas vem sendo usado o termo humanização, com os mais diversos sentidos, podendo ocorrer em diversas áreas. Sempre que se recorre à humanizaçáo, abrem-se caminhos para condiçóes melhores e mais humanas aos agentes envolvidos.

De acordo com Lima [15], a palavra "humanização" deriva do conceito "humanismo", que, no século XXI, demonstrava a solidariedade com a natureza, com ênfase na harmonia entre a razão e o sentimento. Relacionado à saúde, o termo "huma- 
nismo" foi tema de muitas discussóes políticas, que estabeleceram que o termo humanização referia-se ao cuidado e à valorização da intersubjetividade das relaçôes humanas.

$\mathrm{O}$ ato de humanizar, para Casate [16], simula trazer de volta a importância dos sentimentos, visto que estes são inseparáveis dos aspectos físicos do paciente. É uma atitude ética e presente em todo ser humano e que deve ser reforçada. A humanização no atendimento é uma forma de identificar e valorizar o sentido que o sofrimento pelo adoecer traz ao paciente, reconhecendo e trabalhando as relaçóes interpessoais neste processo.

Desse modo, a humanização está vinculada não apenas à valorização do cuidado, mas também às questóes éticas, às científicas e aos direitos do paciente, valorizando a sua individualidade, bem como sua dignidade, autonomia e sua subjetividade [17].

\section{Humanização na assistência ao parto}

A humanização da assistência, nas suas muitas versóes, expressa uma mudança na compreensão do parto como experiência humana e, para quem o assiste, uma mudança no que fazer diante do sofrimento do outro humano. O enfermeiro atua desenvolvendo uma relação de escuta e confiança, tornando esta relação respeitosa na qual é fundamental a existência da empatia na relaçáo enfermeiro-parturiente, tornado esta a protagonista do parto [10].

De acordo com Patah [18], observa-se a existência de três modelos distintos de assistência ao parto. Um seria o modelo altamente medicalizado, focado na hospitalização, grande uso de tecnologias, e elevada utilização de intervenções. $\mathrm{O}$ modelo menos medicalizado, chamado de Humanizado, seria aquele que privilegia o bem-estar da parturiente e também de seu filho, apoia a presença de acompanhantes e a parturiente escolhe a posição que deseja no momento do parto. O enfermeiro obstétrico atua diretamente no procedimento, e no modelo intermediário entre o uso intensivo de tecnologia médica e a assistência pouco intervencionista.

É interessante notar o contraponto entre os modelos; um, altamente medicalizado, tecnicista, institucional e assistido prioritariamente por médico; e outro, não intervencionista, não necessariamente institucional e assistido prioritariamente por enfermeiro obstetra.

Nota-se claramente que a mudança de paradigma assistencial ao parto - de médico para enfer- meiro obstetra - é fundamental para o processo de humanização da atenção ao parto.

Esta mudança de paradigma, certamente, apresenta vários pontos de resistência, que incluem, entre outros, a luta por mercado de trabalho, a luta pelo poder entre categorias profissionais, seja entre categorias de enfermeiros, seja entre médicos e enfermeiros, seja de escolha do profissional pela própria paciente, além de aspectos legais de competência. Garcia [19] propóe formas de atuação para a resolução de tais conflitos.

Hoje nota-se que muitas mulheres optam pelo primeiro modelo, por supostamente reduzir a dor, modismo ou influência de seu obstetra. Nas décadas de 60 e 70 foi observado um grande aumento na incidência de cesáreas. Isso ocorreu porque nessa época a medicina obteve avanços que passaram a proporcionar açóes e procedimentos apresentados como mais seguros. Observa-se, no entanto, que a adoção de um modelo medicalizado, por ser mais intervencionista, resultou em excesso de intervençôes, muitas vezes desnecessárias, e na diminuição da participação de enfermeiro obstetra na atenção ao parto [10].

Em decorrência de tais observaçóes as políticas de saúde buscam estimular o parto normal. Como exemplo, o Ministério da Saúde do Brasil lançou campanhas e materiais didáticos fortalecendo essa prática [20].

Em 1996, a Organização Mundial da Saúde criou o «Guia Prático para a Assistência ao Parto Normal» [20], tendo como intuito estimular a sua prática e orientar uma assistência adequada. Este guia, apresentado como material didático, está estruturado em quatro grandes grupos de procedimentos: 1) Práticas úteis que devem ser estimuladas; 2) Práticas prejudiciais e ineficazes que devem ser evitadas; 3) Práticas em relação às quais não existem evidências para apoiar uma recomendação clara e devem ser realizadas com maior atenção, até que mais estudos esclareçam sua validação; e 4) Práticas frequentes utilizadas de maneira inadequada [21]. Segundo Carvalho [22], a literatura mostra que ainda alguns procedimentos considerados inadequados e que possuem evidência científica que comprovam malefícios são usados rotineiramente, levando a uma assistência de risco a parturiente.

Após seu lançamento, o Ministério da Saúde do Brasil, no ano de 1998, normatizou a assistência ao parto através da portaria n. 2815 de maio de 1998, descrevendo o Grupo de Procedimentos 
para Assistência ao Parto Normal sem Distócia realizado por enfermeiro obstetra. Com base nesta portaria e outras leis, como a $\mathrm{n}^{\circ} 7498$ e o decreto 94.406 de 08 de junho de 1987, as atribuiçóes desse profissional foram definidas oficialmente pela portaria 163 , autorizando-o a realizar partos e emissão de guias de autorização de internação hospitalar [23].

A atuação da enfermagem obstétrica deve ter como princípio norteador o acolhimento às gestantes, o entendimento dos vários significados que aquela gestação tem para a mulher e para a sua família, proporcionando uma forma de diálogo aberto, franco, sem julgamentos e preconceitos.

As políticas de saúde estimulam a atuação da enfermagem obstétrica na assistência ao parto, pelo fato desse profissional cuidador constituir um agente que pode contribuir constantemente para uma assistência holística e humana. Segundo relatos descritos na literatura, há uma grande diferença entre a assistência médica obstétrica e a assistência da enfermagem obstétrica. Essa diferença está na filosofia desta atenção, sendo a enfermagem mais direcionada no cuidar da mulher em um contexto acolhedor e familiar, mais sensível aos sentimentos e aos eventuais sofrimentos durante o parto $[7,23]$. Difere, nesta filosofia, a atençáo oferecida por profissional médico, com enfoque dirigido à identificação de risco, intervenção e tratamento.

Pereira et al. [24] citam em relação às questões éticas e políticas, que a humanização da assistência ao parto está direcionada aos direitos humanos da mulher, da criança que irá nascer e também da família. Assim, a humanização visa promover a autonomia, a liberdade de escolha, equidade, e a evitar qualquer violação de direitos nos serviços de saúde.

Com tais direcionamentos, muitos países já estão incorporando a participação dos pais e familiares na hora do trabalho de parto, criando locais para a assistência mais parecidos com o ambiente doméstico, oferecendo ambiente acolhedor, com vistas a aumentar a satisfação da gestante e diminuir o estresse, medo e outros sentimentos negativos para as gestantes que preferem pouca ou nenhuma intervenção médica, podendo oferecer assistência desde o pré-natal até o parto. Podem ser criados em ambiente hospitalar ou unidades independentes. Ambientes acolhedores fazem com que a parturiente se sinta em casa [25].

\section{Resultados e discussão}

Com fácil acesso à informação e a conscientização de seus direitos, as mulheres passaram a exigir seus direitos de cidadania e várias políticas foram criadas a fim de respeitá-las. Tais políticas surgiram tanto de órgáos governamentais quanto de ONGs, resultando em movimentos sociais e ampla divulgação nas variadas mídias existentes. Não foi diferente com relação ao parto e nascimento humanizados, para os quais o Ministério da Saúde do Brasil implantou normas que impulsionaram os serviços e açóes de saúde para atender o requisito de humanização. Dessa forma, foi proposta uma forma de assistência ao parto cujo objetivo, a princípio, era superar o modelo focado no profissional médico e nas intervençóes, muitas vezes desnecessárias [25].

A saúde materno-infantil, de acordo com as linhas propostas pelo Ministério da Saúde do Brasil, passou a exigir dos profissionais de saúde melhor qualificação e competência para realizar a assistência à mulher e ao recém-nascido, seja no pré-natal, no trabalho de parto, no puerpério, no planejamento familiar e na assistência imediata ao recém-nascido. Assim, o profissional é visto como um ator capaz de realizar o atendimento com boa qualidade, respeitando, não apenas os aspectos físicos, como também os aspectos emocionais [26].

Nesse contexto, o termo "humanização" passou a ocupar lugar de destaque. A humanização na assistência obstétrica passou a ser um ponto importante na atenção, pois "expressa uma mudança na compreensão do parto como experiência humana” [27]. A assistência humanizada abrange conhecimentos, práticas e açôes que direcionam para a promoção do parto e do nascimento saudável além da prevenção de adoecimentos e mortes maternas e perinatais, utilizando-se de poucas intervençóes [27].

Versiani et al. [26] relatam que o parto é um momento muito importante na vida de uma mulher; é um período curto, mas que provoca grandes alteraçóes na fisiologia da mãe e do feto que está para nascer. A assistência obstétrica humanizada é então uma proposta de proteger a espontaneidade do processo, embora deva contemplar a disponibilidade efetiva de intervençóes oportunas, caso seja necessário corrigir desvios da normalidade.

A assistência obstétrica humanizada considera não apenas a mulher, que está ali para o parto, e o recém-nascido, mas também seus familiares, pois estes representam apoio para a gestante naquele 
momento de tantas incertezas. Visa, assim, um acolhimento humanizado pautado no respeito e dignidade [26].

A questão da humanização, principalmente relacionada ao parto, trouxe à tona vários estudos, apresentando formas mais naturais para a assistência ao parto e a maneira de abordagem à paciente [28].

Em grande parte do mundo, as mulheres aprenderam a temer o parto/nascimento, por sua forte ligação com a dor. Na Bíblia Sagrada, no livro do Gênesis (3:16), Deus disse a mulher: "multiplicarei os sofrimentos de teu parto; darás à luz com dores...”. A dor do parto normal está associada à ideia de sofrimento, que em culturas diferentes é esperada por muitas mulheres. O parto normal deixou de ser um evento privativo da família, pois com o surgimento da obstetrícia como ciência passou a ser um evento institucionalizado. O Brasil passou a ser reconhecido entre os países com a mais alta taxa de parto cesáreo. Um fato preocupante é a cesárea a pedido, como estratégia para evitar a dor ou por conveniência da equipe médica. Em consequência de atos cirúrgicos desnecessários, houve um aumento da morbimortalidade materna e perinatal [28].

Desse modo, a humanização do parto normal pode reduzir este medo e, consequentemente, as altas taxas de parto cesáreo de morbimortalidade materna e perinatal. Mesmo assim nas sociedades tecnocráticas existem pontos de resistência para a implementação deste enfoque e redução de intervençóes, particularmente utilizando a justificativa de possível aumento de risco. É importante observar que as experiências demonstram que a segurança, tanto da paciente, $\mathrm{RN}$ e da equipe de saúde não é comprometida, desde que existam açóes e procedimentos normatizados para a identificação e tratamentos de anormalidades do parto a serem implementados.

A humanização não compromete a segurança e não constitui contradiçóes. O parto humanizado é abordagem segura.

O parto deve ser visto como uma condição natural e fisiológica. A gestante é estimulada a compreender mais sobre esse processo, buscando valorizar as relaçóes entre as pessoas ali envolvidas [29].

"Humanizar a assistência hospitalar é dar lugar não só à palavra do usuário como também à palavra do profissional de saúde, de forma que tanto um quanto o outro possam fazer parte de uma rede de diálogo. Cabe a esta rede promover as açóes, campanhas, programas e políticas assistenciais baseadas na dignidade ética da palavra, do respeito, do reconhecimento mútuo e da solidariedade [29]".

Portanto assistência humanizada se inicia quando os profissionais de saúde são capazes de sentir e interagir com as paciente e também com seus familiares, criando uma relação de respeito aos direitos humanos.

Tal meta deve encontrar apelo já durante o pré-natal, desde a captaçáo e recepção inicial da gestante e as consultas subsequentes, a paciente deve receber acolhimento enfocando humanização, além da imprescindível aplicação do conhecimento técnico. Este tipo de atenção humanizada, iniciada e mantida durante todo o acompanhamento pré-natal, encontra, no enfermeiro obstetra, um ator importantíssimo, como descrito por Garcia [30], em seu texto sobre a necessidade de inclusão deste tipo de profissional nas equipes de saúde da rede básica de atenção à saúde, para a realização de pré-natal.

Segundo Priszkulnik e Maia [29], para a realização adequada do parto humanizado é preciso atentar a algumas ações nas várias fases de assistência: No momento da admissão é importante preservar a privacidade da gestante, mas deixar sempre o acompanhante de sua escolha acompanhá-la; $D u$ rante o trabalho de parto, manter o acompanhante desejado, oferecer líquidos via oral para prevenir eventos de hipoglicemia, além de mantê-la hidratada, amparar sempre emocionalmente, oferecer informações toda vez que ela se sentir insegura, não apenas para ela, mas também para o acompanhante, estimular a gestante a deambular, procurar acima de tudo manter o bem-estar físico e emocional da parturiente, auscultar o feto regularmente, cortar o cordão umbilical apenas após cessar os batimentos; Com relação à posição do parto, adotar a posição vertical, que facilite o evoluir do feto pelo canal de parto; No controle da dor, evitar a utilização de drogas analgésicas, optando sempre por métodos não medicamentosos como massagens, relaxamento, banhos de imersão, entre outros. Após a dequitação, realizar o exame da placenta, e recorrer ao mínimo uso de ocitócicos especialmente nos casos com possível risco de hemorragia; E no final, estimular a amamentação nas primeiras horas, proporcionando, assim, o bem-estar fetal e a liberação endógena de ocitocina [29]. 
De acordo com a assistência humanizada no parto, náo é ideal sugerir à parturiente que fique acamada, deve-se estimular deambulação durante o trabalho de parto, pois existem evidências científicas do seu benefício para a parturiente e para o feto, como regularização das contraçóes, diminuição do tempo de trabalho de parto e uma melhor tolerância da vivência da dor. Portanto, deve ser estimulada a andar e ela própria escolher a melhor posição para ficar a qualquer momento, exceção ao decúbito dorsal horizontal. Após o nascimento o recém-nascido deve ficar junto à mãe, proporcionando a amamentação logo após o nascimento, cujo objetivo é intensificar o vínculo mãe e filho. A comunicação deve ser um instrumento muito trabalhado com os profissionais que estão na assistência, visto que permite uma troca sensível de informaçóes permitindo uma relação mais afetiva [10].

$\mathrm{O}$ acolhimento é um instrumento essencial na humanização. É responsável por recepcionar a mulher em sua chegada à maternidade, ou à casa de parto. Requer sensibilidade por parte dos profissionais ao escutar queixas, preocupações, angústias, e procurar realizar uma atenção resolutiva. Nesse momento são simples atitudes que fazem grande diferença como apresentar-se, chamar a mulher pelo nome, dispor de informaçóes sobre os procedimentos que serão realizados, ouvi-la e acima de tudo valorizar suas queixas [31].

A humanização do parto não está ligada apenas à realização do parto normal, mas sim em realizar um atendimento dando a liberdade de escolha dos procedimentos. Está ligada à "filosofia de vida e percepção de si e do outro como ser humano". Os meios imprescindíveis estão ligados à sensibilidade do profissional, as formas de comunicação e meio de transmitir informaçóes, não apenas à parturiente como também aos familiares e acompanhantes [32].

O acompanhante torna-se, neste contexto, um ator essencial, pois conforta a mulher, ajuda a aliviar as dores e as tensôes presentes. Assim, os acompanhantes também necessitam de apoio e colaboração da equipe profissional. Por sinal, esta deve estar sensibilizada sobre a importância do acompanhante para a parturiente e preparada para trabalhar junto a ele, oferecendo informaçóes sobre as condutas [33].

$\mathrm{O}$ contato inicial entre o recém-nascido e seus pais é considerado molde das relações futuras, o momento do nascimento é o mais rico para a formação do vínculo mãe e filho. Assim os profissionais devem estar cientes dessa atitude, procurando sempre proporcioná-lo logo que possível, realizando apenas os cuidados que realmente são necessários aos recém-nascidos naquele momento [10].

Nos casos de recém-nascidos prematuros, serão necessários cuidados maiores. A família deve estar preparada e orientada com vistas a diminuir as ansiedades. $\mathrm{O}$ apoio à parturiente e aos familiares deve ser redobrado, amparando-os e dando suporte psicológico. O contato com outras mães com recém-nascidos prematuros ajuda a fortalecer laços entre mãe e $\mathrm{RN}$, troca positiva de experiências sobre os cuidados especiais e testemunhos reais, resultando em experiências altamente positivas de redução de ansiedades [34].

\section{Concretizaçáo do atendimento e assistência hu- manizada no contexto físico, mental, emocional e social}

Toda instituição que realiza procedimentos obstétricos deve estar voltada para a qualidade, que compreende, entre outros elementos, a humanização. É responsabilidade tanto das instituiçóes como dos profissionais que nela atuam acolher com dignidade a mulher e o recém-nascido. A humanização torna-se, portanto, uma adoção, por parte dos profissionais, de valores, solidariedade e estabelecimentos de vínculos com os usuários [32].

"A atenção com qualidade e humanizada depende da provisão dos recursos necessários, da organização de rotinas com procedimentos comprovadamente benéficos, evitando-se intervenções desnecessárias, e do estabelecimento de relaçóes baseadas em princípios éticos, garantindo-se privacidade e autonomia e compartilhando-se com a mulher e sua família as decisóes sobre as condutas a serem adotadas [32]”.

Os Centros de Parto Normal foram uma forma de fortalecer a humanização do parto e nascimento. Esses foram sugeridos pela OMS visando à alteração no olhar profissional sobre a parturiente e seus familiares. Foi oficializado com a Portaria 985/99 [37] constituindo-se em unidades de assistência ao parto normal, distantes de centros cirúrgicos. O local é disposto de uma forma mais acolhedora, destinado a receber a parturiente e seus acompanhantes, propondo um parto participativo e ativo [32].

Esses centros surgiram como forma de propor- 
cionar o direito à privacidade e também à dignidade da parturiente, de realizar o parto em um local com aspecto mais familiar ao mesmo tempo com toda segurança tanto para a parturiente quanto para o recém-nascido, dispondo de recursos para casos especiais [36]. A protagonista do processo é a parturiente e o profissional que a assiste é o enfermeiro obstetra.

O Ministério da Saúde do Brasil ao adotar os preceitos recomendados pela Organização Mundial da Saúde colocam como diretrizes de assistência humanizada diversas práticas consideradas, desde o pré-natal, quando se avaliam as possíveis complicaçóes; planejamento, onde e como será assistido o nascimento; o respeito sobre as escolhas da gestante, sempre fornecer informaçóes a gestante e seus familiares quando necessário; na admissão, deve ser acolhida de forma que se sinta segura, respeitar sua privacidade e sua escolha do acompanhante. Durante o trabalho de parto, a parturiente e seu acompanhante são informados constantemente sobre a evolução do trabalho de parto pelo enfermeiro obstétrico que os assiste. O controle da dor deve ser feito por meios náo invasivos e não farmacológicos [36].

O parto humanizado, seja em centros especializados ou em qualquer outro tipo de instituição, deve proporcionar a participaçáo ativa da parturiente nas decisóes, como a escolha da posição, utilização de todas as formas não farmacológicas para alívio da dor (como água morna, compressas, etc.). Devem-se estimular algumas medidas como a posição vertical para ajudar na rotação e expulsão da criança, realizar massagens, fazer exercícios e ser assistida por um profissional capacitado e que ofereça as orientaçóes que se fizerem necessárias [29].

A estrutura física interfere, muitas vezes, na realizaçáo do parto humanizado.

"Assim, algumas modificaçóes dentro da estrutura hospitalar serão necessárias para a efetivação do parto humanizado; medidas simples, que priorizem fundamentalmente a privacidade da parturiente, a presença do acompanhante e o espaço para deambulaçáo. Em um primeiro momento, parecerá que o investimento será gerador de despesas e custos à instituição hospitalar, porém, com a adoção das medidas humanizadoras de parto, a economia de material e, em especial, de medicamentos será substancial. Partindo desse ponto de vista, a adoção dos procedimentos relativos ao parto humanizado pode oferecer às operadoras de planos de saúde, sobretudo as que contam com hospital próprio, uma ferramenta de gestâo baseada na qualidade do atendimento e na satisfaçấo da cliente; trará em seu escopo uma diminuição dos custos assistenciais relativos ao período de parto e puerpério. Como a demanda faz o mercado, as operadoras poderão oferecer a suas clientes, como diferencial de qualidade, a possibilidade de uma parturição em um ambiente hospitalar menos inóspito, mais acolhedor e mais humanizado" [29].

Nos centros hospitalares, trabalhar a humanização do atendimento à parturiente constitui um grande desafio. É difícil e demanda tempo para sensibilizar a equipe, requer paciência, capacitação e perseverança, porém é muito gratificante e recompensadora [29].

\section{Inter-relaçáo entre os profissionais de saúde no centro obstétrico com suas pacientes}

Segundo Moreira et al. [32], a relação entre os profissionais e a parturiente resgata e fortalece o processo de humanização no parto. Em meio a tantas inseguranças e medos, a relação mais próxima traz conforto e segurança à parturiente.

A comunicação neste contexto é ponto chave, pois é através dela que se consegue proporcionar bem-estar e segurança à parturiente. Nas relaçóes interpessoais, a comunicação torna-se uma forma terapêutica, quando é colocada de forma adequada, visando à individualidade [37].

As relaçóes humanas são fenômenos que interferem consideravelmente para o bem-estar das pessoas que necessitam de cuidados. O profissional de saúde é, assim, estimulado a compreender as mensagens visando criar laços afetivos, tornando a assistência mais confortável para o paciente [37].

\footnotetext{
"O relacionamento e suas competências são evidentes em qualquer relação particular com outras pessoas, grupos, objetos ou ambientes e influenciaráo e determinarão o estado da relação estabelecido pela pessoa. Relacionamento é uma ideia central para os profissionais de saúde e aplicável a todas as especialidades. Rompimentos e/ou instabi-
} 
lidade nas competências de relacionamento com os clientes podem contribuir para perturbaçóes biológicas, psicológicas e sociais destes. O relacionamento humano também é pertinente como um caminho para a intervenção, segundo suas competências, oferecendo o meio pelo qual os profissionais podem iniciar e manter as mais úteis e eficientes relaçôes com os clientes [37]".

Os profissionais da obstetrícia necessitam criar vínculos entre a mente e o corpo, fortalecendo o "amor ao próximo", pois só assim conseguirão realmente realizar uma assistência de qualidade. A solidariedade e o amor ao próximo ultrapassam as ações e cuidados, como se fortalecessem e valorizassem a qualidade de vida do outro. Isso constitui um grande desafio para a maioria dos profissionais de saúde nos dias atuais [37].

"Para que ocorra o cuidado de qualidade à gestante, parturiente e puérpera no processo de ser mãe, o profissional precisa sensibilizar-se com a maternidade, de modo singular, em relação a cada mulher. Ao se estabelecer a conexão, fruto de relaçóes humanas que promovem o envolvimento, produz-se o bom atendimento [37]".

Moreira et al. [32] citam que os cuidados obstétricos, focados nas reais necessidades das mulheres, caracterizam direito total e conferem autonomia à parturiente, sendo a comunicação um fator importante neste contexto. Por isso é necessário que os profissionais de saúde ligados a esta área desenvolvam uma boa comunicaçáo com as parturientes, informando-as de todos os procedimentos.

O contato dos profissionais com a parturiente deve ser voltado para o fortalecimento dos aspectos emocionais, ajudando-a na superaçáo dos medos, ansiedades e tensôes. A relação bem próxima poderá amenizar esses sentimentos [32].

Behruzi et al. [38] discutem, em seu estudo, a questáo do parto humanizado em casos de gravidez de risco. Segundo os resultados do estudo, existem fatores que facilitam o parto humanizado, como o compartilhamento da tomada de decisão entre os médicos e a paciente; uma comunicação efetiva entre toda equipe com a paciente levará a um ambiente livre de tensóes para ambos.
Todos os profissionais que trabalham na assistência ao parto, sejam médicos, enfermeiros, técnicos e auxiliares de enfermagem e mesmo os funcionários administrativos, precisam ser capacitados e sensibilizados quanto à humanização do cuidado, incluindo questóes relacionadas ao acolhimento. Tal acolhimento, quando feito por um profissional capacitado e bem orientado sobre a importância de se acolher a gestante e seus familiares, levará esta família a sentir-se segura, gerando assim vínculos mais consistentes. É preciso atentar para os cuidados fisiológicos e emocionais da parturiente, proporcionando uma experiência boa, minimizando a insegurança e as angústias [32].

A enfermagem mais do que uma atividade técnica, embasada em técnica científica, é também arte, que o profissional usa para se aproximar de outras pessoas e estabelecer certo grau de relação e confiança [12]. A comunicação dentro desse processo é uma ferramenta de trabalho favorecedora da interação entre a equipe multiprofissional, o cliente e sua família. Dessa forma, o enfermeiro obstetra deve estar sempre presente, estabelecendo uma troca bilateral de respeito pela dignidade do ser humano [12].

A humanização é realizada, muitas vezes, por meio de palavras de carinho e conforto, transmitindo assim segurança a gestantes e familiares durante as muitas atividades realizadas pela equipe de enfermagem na assistência obstétrica [12].

Santos [39] cita que é preciso evoluir para um novo modelo de cuidados para a gestante, transformar profissionais focados nas técnicas em profissionais com olhares mais humanos, inspirados pela paz e equilíbrio.

Behruzi [38] destaca que a humanização da assistência ao parto em um hospital altamente especializado deve procurar atender todos os aspectos, sejam eles fisiológicos, psicológicos, bem como da assistência ao parto, respeitando sempre crenças, medos, valores e necessidades das gestantes e de seus famíliares. A integração de profissionais competentes, aliados ao uso da tecnologia para melhorar o nível de certeza e segurança no acompanhamento de gestantes de alto risco, são fatores positivos para a implantação do cuidado humanizado.

Seja em instituiçóes de alto nível de complexidade, seja em maternidades simples, centros de parto normal ou casas de parto, o enfermeiro obstetra tem papel fundamental no processo de humanização. Ele é o profissional que exemplifica, através de 
atuação e liderança, tanto para a paciente, quanto para a equipe de saúde, a humanização da atenção. Detém o saber técnico e atua como enfermeiro, ou seja, cuidando [19].

As atuais propostas de humanização do parto indicam alternativas para redução dos altos índices de cesariana nas instituiçóes hospitalares, e ainda percebe-se que as condutas tomadas durante o processo do parto não condizem com as políticas públicas de assistência à saúde da mulher. Portanto, não se pode esquecer a importância do pré-natal para a gestante juntamente com o cuidado da enfermagem que tem por finalidade promover um bom desenvolvimento gestacional, prevenir situaçóes de risco.

Evidencia-se que com a humanização do parto, a mulher passa a ser a protagonista neste processo, vivencia este acontecimento de forma que o parto deixa de ser apenas evento biológico, mas também experiência humana.

\section{Conclusão}

É importante que o profissional de saúde observe a mulher como um ser único, respeitando seus direitos e desejos, reconhecendo a individualidade de cada paciente, tornando, assim, sua assistência humanizada.

Observa-se que muitas políticas de humanização da assistência obstétrica têm sido criadas, inclusive por demanda da própria sociedade. A capacitação, atualização e inclusão do tema na graduação dos profissionais da saúde têm recebido atenção e investimentos. Há também muitas reflexôes teóricas que enfatizam esse tema. Deve-se buscar continuamente o aprimoramento profissional através de educação continuada, cursos capacitantes. Mesmo com sobrecarga de trabalho, por redução do quadro de funcionários, baixos salários, falta de materiais, estrutura física inadequada, o profissional da área da saúde deve manter o compromisso do atendimento com empatia, mostrando seu respeito e suas preocupaçóes com a gestante e seus familiares promovendo atendimento humanizado.

Este estudo possibilitou identificar várias publicaçóes científicas sobre a importância da humanização da assistência ao parto e realizar análise, incluindo a questão de como deve ser tratada a gestante e seus familiares pelos profissionais da área da saúde, desde sua internação até o momento da alta hospitalar. A enfermagem encontra-se como elo entre esses atores e como a sua essência está ligado ao cuidado. É um profissional fundamental para o desenvolvimento da humanização, dentro deste contexto.

\section{Referências}

1. Schwonke CR, Lunardi Filho WD, Lunardi VL, Santos SS, Barlem EL. Perspectivas filosóficas do uso da tecnologia no cuidado de enfermagem em terapia intensiva. Rev Bras Enferm 2011;64(1):189-92.

2. Domingos EL. A humanização e seus preceitos para o cuidado. [online]. 2007 [citado 2013 dez 11]. Disponível em URL: http://www.pesquisando.eean.ufrj.br

3. Oliveira ME. Mais uma nota para a melodia da humanização. In: Oliveira ME, Zampieri MF, Bruggemann OM. A melodia da humanização: reflexos sobre o cuidado durante o processo do nascimento. Florianópolis: Cidade Futura; 2011. p.121.

4. Oliveira IC, Cutolo LR. Humanização como expressão de integridade. Mundo Saúde 2012;36(3):502-6.

5. Corbani NM, Brêtas AC, Matheus MC. Humanização do cuidado de enfermagem: o que é isso? Rev Bras Enferm 2009;62(3):349-54.

6. Barbosa IA, Silva MJ. Cuidado humanizado de enfermagem: o agir com respeito em um hospital universitário. Rev Bras Enferm 2007;60(5):546-51.

7. Busanello J, Kerber NP, Fernandes GF, Zacarias CC, Cappellaro J, Silva ME. Humanizaçáo do parto e a formação dos profissionais da saúde. Ciênc Cuid Saúde 2011;10(1):169-75.

8. Conselho Federal de Enfermagem. Resolução 240/2000 - Revogada pela Resolução Cofen 311/2007. Aprova o Código de Etica dos profissionais de enfermagem e dá outras providências [citado $2013 \mathrm{dez} 10$ ]. Disponível em: URL: http://novo.portalcofen.gov.br/node4280.

9. Brasil. Ministério da Saúde. Portaria no 569/GM, de 01 de junho de 2000. Institui o programa de humanização no pré-natal e nascimento no âmbito do Sistema Único de Saúde-SUS. Diário Oficial da União, Brasília, DF; 1998 jun 02; Anexo II. p.7.

10. Caires TL, Santos RS. O saber da enfermagem obstétrica e suas contribuiçóes sociais para a autonomia da parturiente. Rev Enferm Prof 2014;1(2):422-35.

11. Brasil. Ministério da Saúde. Portaria n.1.459, de 24 de junho de 2011. Institui, no âmbito do Sistema Único - SUS - a Rede Cegonha [online]. Diário Oficial da União, Brasília (DF); 2011.

12. Rocha D, Carvalho R. Humanização da assistência: o que pensam os estudantes de enfermagem? Einstein (São Paulo) 2007;5(4):315-20.

13. Marconi MA, Lakatos EV. Fundamentos de metodologia científica. 6a ed. São Paulo: Atlas; 2005.

14. Patrias K, ed. Citing medicine: the NLM style guide for authors, editors, and publishers [Internet]. 2nd ed. Bethesda (MD): National Library of Medicine (US); 2007.

15. Lima AP. A humanização do cuidado pré e pós-natal em uma organização não governamental [dissertação]. São Paulo: Universidade de Sáo Paulo, Instituto de Psicologia; 2010.

16. Casate JC, Corrêa AK. A humanização do cuidado na formação dos profissionais de saúde nos cursos de graduação. Rev Esc Enferm USP 2012; 46(1):219-26. 
17. Almeida DV. O ensino da humanização nos currículos de graduação em enfermagem [dissertação]. Sáo Paulo: Universidade de São Paulo, Escola de Enfermagem; 2007.

18. Patah LE, Malik AM. Modelos de assistência ao parto e taxa de cesárea em diferentes países. Rev Saúde Pública 2011;42(1):185-94.

19. Garcia AS, Lippi UG, Garcia AS. O parto assistido por enfermeira Obstetra: perspectivas e controvérsias. Rev Bras Promoç Saúde 2010;23(4):380-8.

20. Organização Mundial de Saúde - OMS. Assistência ao parto normal: um guia prático. Genebra: OMS; 1996.

21. Silva NC, Ruela LO, Resck ZM, Andrade MB, Leite EP, Silva MM, Lunes DH. Humanização da assistência de enfermagem em uma unidade de internação obstétrica. Enferm Foco 2013;4(2):88-91.

22. Carvalho VF, Kerber NP, Busanello J, Costa MM, Gonçalves BG, Quadros VF. Práticas prejudiciais ao parto: relato dos trabalhadores de saúde do sul do Brasil. Rev Rene 2010;11(Suppl):92-8.

23. Prata JA, Progianti JM, Pereira AL. O contexto brasileiro de inserção das enfermeiras na assistência ao parto humanizado. Rev Enferm UERJ 2012; 20(1):105-10.

24. Pereira AL, Moura MA, Souza IE, Tyerrel MA, Moreira MC. Pesquisa acadêmica sobre humanização do parto no Brasil: tendências e contribuiçôes. Acta Paul Enferm 2007;20(2):205-15.

25. Hodnett ED, Downe S, Walsh D. Ambiente hospitalar alternativo versus ambiente convencional para o parto [online]. 2012 [citado 2015 Mar 17]. Disponível em URL: http://www.cochrane.org/pt/CD000012/.

26. Porfirio AB. A atualização do habitus da enfermeira obstétrica no processo de implantação do modelo humanizado na maternidade Alexander Fleming [dissertação]. Rio de Janeiro: Universidade do Estado do Rio de Janeiro / UERJ; 2011.

27. Versani CC, Mendonça JM, Vieira MA, Sena RR. Maternidade segura: relato de experiência. Rev APS 2008;11(1):109-14.

28. Mouta RJ. A reconfiguração do espaço social da maternidade Leila Diniz: a luta das enfermeiras obstétricas pela implantação do modelo humanizado de assistência ao parto [tese]. Rio de Janeiro: Universidade do Estado do Rio de Janeiro / Faculdade de Enfermagem; 2009.
29. Almeida NA, Medeiros M, Souza MR. Perspectivas de dor do parto normal em primigestas no período pré-natal. Texto Contexto Enferm 2012;21(4):819-27.

30. Priskulnik G, Maia AC. Parto Humanizado: influencias no segmento saúde. Mundo Saúde 2009;33(1):80-88.

31. Garcia SA, Garcia SAL, Lippi UG. A necessidade de inserçáo do enfermeiro obstetra na realizaçáo de consultas de pré-natal na rede pública. Einstein 2010; 8(2):241-7.

32. Brasil. Ministério da Saúde. Pré-natal e puerpério: atenção qualificada e humanizada - manual técnico/ Ministério da Saúde, Secretaria e Atenção à Saúde, Departamento de Açóes Programáticas Estratégicas. [Série A. Normas e Manuais Técnicos] - [Série Direitos Sexuais e Direitos Reprodutivos]. Brasília: Ministério da Saúde; 2005.

33. Moreira KA, Araújo MA, Fernandes AF, Braga VA, Marques JF, Queiroz MV. O significado do cuidado ao parto na voz de quem cuida: uma perspectiva a luz da humanização. Cogitare Enferm 2009;14(4):720-8.

34. Moura FM, Crizostomo CD, Nery IS, Mendonça RC, Araújo OD, Rocha SS. A humanização e a assistência de enfermagem ao parto normal. Rev Bras Enferm 2007;60(4):452-55.

35. Siqueira MB, Dias MA. A percepção materna sobre vivência e aprendizado de cuidado de um bebê prematuro. Epidemiol Serv Saúde 2011;20(1)27-36.

36. Brasil. Ministério da Saúde. Portaria no 985/GM, de 05 de agosto de 1999. Cria o Centro de Parto Normal CPN. Diário Oficial da União, Poder Executivo, Brasília (DF); 1999 Ago 08; Seção 1:51.

37. Gomes AR, Pontes DS, Pereira CC, Brasil AO, Moraes LC. Assistência de enfermagem obstétrica na humanização do parto normal. Recien - Rev Cient Enferm 2014;4(11):23-27.

38. Gotardo GI, Silva IA. Refletindo sobre a prática obstétrica à luz de um modelo de relacionamento humano. Cienc Cuid Saude 2007;6(2):245-51.

39. Behruzi R. What are the components of humanized childbirth in a highly specialized hospital?: an organizational case study [These]. Montréal: Université de Montréal / Faculté de médecine; 2011.

40. Santos ML. Challenges of a philosophy for the humanization of childbirth. Rev Tempus Actas Saúde Col 2010;2(1):65-76. 